\title{
Association analysis and in-vitro anti-fungal assay reveal a role for the Pinus monticola PR10 gene (PmPR10-3.1) in quantitative resistance to white pine blister rust
}

Jun-Jun Liu ( $\boldsymbol{\sigma}$ jun-jun.liu@canada.ca )

Canadian Forest Service https://orcid.org/0000-0002-9745-8258

Humberto Fernandes

Polish Academy of Sciences

Arezoo Zamany

Canadian Forest Service

Michal Sikorski

Polish Academy of Sciences

Mariusz Jaskolski

A. Mickiewicz University

Richard A. Sniezko

USDA-FS

\section{Research article}

Keywords: Association analysis, Global gene expression study, In-vitro anti-fungal array, Pathogenesisrelated protein class 10 (PR10), Quantitative resistance (QR), White pine blister rust (WPBR)

Posted Date: June 4th, 2019

DOI: https://doi.org/10.21203/rs.2.10026/v1

License: (c) (i) This work is licensed under a Creative Commons Attribution 4.0 International License. Read Full License

Version of Record: A version of this preprint was published at Genome on July 1st, 2021. See the published version at https://doi.org/10.1139/gen-2020-0080. 


\section{Abstract}

Background Pathogenesis-related (PR) proteins play important roles in plant defense response. However, functional investigation of PR10 genes is still limited and their physiological roles have not been conclusively characterized in biological processes of forest conifer trees. Results To elucidate the biological roles of PR proteins of class 10 (PR10) in tree resistance to pathogens, in the present study we identified multiple novel members in the complex PmPR10 family of western white pine (Pinus monticola Douglas ex D. Don). Phylogenetic analysis revealed that PmPR10 genes were grouped into clusters and sub-clusters, showing a relatively high synteny between the same cluster/sub-cluster across different species of five-needle pines. RNA-seq-based global gene expression study demonstrated the PmPR10 genes were differentially expressed in response to infection by Cronartium ribicola, an exotic fungus causing white pine blister rust (WPBR) across North America. Among all family members, PmPR10-3.1 transcripts were significantly up-regulate at both early and late stages post rust infection. This gene was further revealed to have significant contribution to host quantitative resistance to WPBR by an association study. Moreover, PmPR10-3.1 recombinant protein exhibited inhibitory effects on spore hyphal growth of fungal pathogens $\mathrm{C}$. ribicola, Phoma exigua and P. argillacea by in-vitro antifungal analysis. Conclusion Our results suggest that PmPR10-3.1 may function as an important component in conifer basal immunity for non-specific resistance to a wide spectrum of pathogens.

\section{Background}

Pathogenesis-related (PR) proteins are important components involved in host defense responses to protect plants from environmental biotic and abiotic stressors, and they are grouped into different families based on sequence homology and biological activities [1]. The PR10 family contains a large number of proteins that share some common features, including low-molecular weight (15-20 kDa), acidic pl, a glycine-rich loop motif (GXGGXGXXK), conserved 3-D structure, and cytosolic location [1-3].

Plant PR10 proteins are universal in the plant kingdom as a family with multiple members. They usually show differential expression across plant organs and development stages in response to environmental stressors, suggesting potential roles in various biological processes for plant development, growth, and defense against various pathogens and other environmental stress factors [3]. Several angiosperm PR10 genes were expressed in Escherichia coli and their recombinant proteins were analyzed by in-vitro assays. These studies revealed that some recombinant PR10 proteins possess RNase, or anti-microbial activity, as well as ligand binding activity [4-13]. Transgenic plants with over-expression of PR10 genes exhibited enhanced resistance or tolerance to salinity, cold, osmotic stress, and infection by various pathogens [1317]. Evidence accumulated so far indicates that PR10 proteins have multiple functions $[3,14,18]$. Different family members may have adapted different functions although there is high sequence homology and structural similarity among them [19]. The emerging picture strongly suggests that PR10 proteins bind phytohormones and other plant mediators, including the recently included melatonin [20, 21]. However, functional investigation of PR10 genes is still limited and their physiological roles in plant biological processes have not been conclusively characterized [14]. 
The function of the PR10 gene family in five-needle pines is of great environmental and economic importance because these conifers play key roles in forest ecosystems across North America. However, wild populations of North American native five-needle pines have been seriously disturbed by the fungal pathogen Cronartium ribicola (J.C. Fisch.), which causes white pine blister rust (WPBR). Both major gene resistance (MGR) and polygenic quantitative resistance (QR) were detected in a few species of five-needle pines [22]. Although MGR confers a complete immunity to specific isolates, it is overcome by virulent strains in the WPBR pathosystems [23]. For example, $P$. monticola Cr2-controlled MGR can be overcome by $C$. ribcicola avcr2 pathotype. Compared to MGR, QR is generally more durable in plant immune systems with involvement of multiple genetic factors [24]. The complex genetic bases of the observed resistance traits and non-characterized rust genotypes hinder elucidation of genetic mechanisms underlying QR to WPBR. Thus far, quantitative trait loci (QTLs) for genetic resistance to WPBR have not been well characterized in western white pine and other five-needle pines. Moreover, little is known about genetic mechanisms and functional genes underlying QR to WPBR $[25,26]$.

Our previous studies identified several PR10 proteins (PmPR10s) in western white pine (Pinus monticola Douglas ex D. Don) [27]. Expression of the PmPR10 family members was revealed to be differentially regulated during plant development and in response to biotic/abiotic stressors and treatments of plant hormones [18]. However, the molecular functions of PmPR10s in plant response to biotic stressors are still elusive. The aim of this study is to gain a comprehensive understanding of the PmPR10 family expressed during defense response to WPBR, and to further investigate the genetic contribution and functional role of selected family members in disease resistance by association analysis and in vitro antifungal assay. Functional characterization of a PR10 protein with antimicrobial activity facilitates identification of QTLs and biomarkers with application in conventional tree breeding, speeding up selection of host resistance for the control of WPBR in western white pine and related five-needle pines.

\section{Methods}

\section{Identification of PR10s expressed in western white pine defense response}

To gain a global view of PR10 genes expressed in western white pine, PmPR10 proteins identified in a previous study [27] were used as queries for a Blastx search with the lowest E-value < e-05 and minimum length of 100 amino acids in needle and stem transcriptomes in response to infection by C. ribicola [28, 29]. To classify novel PmPR10s and analyze their phylogenetic relationship with other members, putative PR10 sequences were mined out from the genome sequence of sugar pine [29] and transcriptomes of limber pine and whitebark pine [25,31]. The proteins with full-length amino acid sequences were aligned by Clustal Omega with default parameters. An unrooted phylogenetic tree was constructed using the minimum evolution method in MEGA5 software [32] with bootstrap test of 1000 times. Nicotiana tabacum polyketide cyclase-like (Uniprot: Q53HY7) was included as an outgroup [33]. The PR10 genes 
from four five-needle pine species were classified into different groups according to the topology of the phylogenetic tree.

\section{Transcript expression analysis}

Illumina RNA-seq raw reads (SRA run accessions SRR1013833, SRR1013836, SRR1013837, SRR1574690-1574692, and SRR3273235-SRR3273237) were downloaded from GenBank and used to evaluate transcript levels of target genes. The detailed experimental procedures for seedling inoculation, sampling, and RNA-seq analysis were described in a previous study [28, 29]. In brief, one open-pollinated $P$. monticola family (\#3926) was used in RNA-seq analysis. Their seeds were collected from one cone tree with MGR segregation (Cr2/-vs. $\mathrm{cr} 2 / \mathrm{cr} 2$ ) as detected in BC breeding program. Six-month-old seedlings was inoculated in a chamber with day temperatures of $16^{\circ} \mathrm{C}$ and night temperatures of $12^{\circ} \mathrm{C}$, facilitating basidiospore shed. Infected Ribes nigrum leaves were collected from a Ribes garden on Vancouver Island where only pathogenic avcr2 isolates were available. Rust-infected Ribes leaves were laid on a metal mesh above the pine seedlings to shed basidiospores with a spore density $>3,000$ spores per square centimeter, which was counted by placing glass slides at random underneath the mesh during inoculation. Primary needles were collected from at least 10 seedlings individually at 0 - (un-inoculated) and 4-day post inoculation (dpi) and stored at $-80^{\circ} \mathrm{C}$. Resistant (Cr2/-) or susceptible (cr2/ cr2) genotypes were determined using Cr2-linked DNA markers. Total RNA was extracted from approximately five grams of needles pooled from at least 10 seedlings per treatment for RNA-seq analysis.

RNA-seq reads were mapped back to the western white pine reference transcriptome $[28,29]$ using CLC genomics workbench v5.5 with parameters: minimum length of putative exons $=50$, minimum number of reads $=10$, maximum number of mismatches (short reads) $=2$, unspecific match limit $=20$, minimum exon coverage fraction $=0.2$, minimum length fraction (long reads) $=0.9$, minimum similarity fraction (long reads) $=0.9$. Transcript expression values were measured as reads per kilobase of transcript per million mapped reads (RPKM), but only paired reads were calculated. Kal's test was used to compare needle samples post $C$. ribicola infection. T-test was used to estimate statistical significance for differences of transcript levels in the stem tissues between resistant seedlings (stem canker-free) and susceptible seedlings (stem-cankered). P-values were corrected by the false discovery rate (FDR).

\section{Detection of DNA variations and association study}

Eighteen open-pollinated families with a total of 160 seedlings (Supplementary Table S1) were used to explore potential association of PmPR10 genotypes with $P$. monticola DR to $C$. ribicola. Phenotyping of the seedlings for their traits related to QR against WPBR were reported previously [34]. Briefly, seeds were sowed in 2003 and the seedlings were inoculated artificially by basidiospores in fall 2004 at the United States Department of Agriculture Forest Service, Dorena Genetic Resource Center (Cottage Grove, OR). Disease symptoms were assessed on a yearly basis for the next five years. QR levels were ranked as level $0=$ rust dead, $1=$ normal canker growth with aecia development, $3=$ normal canker growth only without 
aecia, 4=normal canker growth without aecia but with partial bark reaction, 5=normal canker growth without aecia but with bark reaction, $6=$ partial bark reaction without aecia, $7=$ bark reaction and partial bark reaction without aecia, $8=$ bark reaction only without aecia, and $10=$ complete resistance as stem symptom-free.

Genomic DNA was extracted from needle tissues for each seedling using a Qiagen DNeasy kit (Qiagen Inc., Mississauga, ON, Canada). Based on PmPR10-3.1 cDNA sequence [27], a pair of gene-specific primers, forward 5'-ACA ACA AGC AGC TTA CGT TTC-3', and reverse 5'- GTT TGG AGT CTG GAC ATA TAG3 ', were designed to amplify genomic DNA. Following gel purification using a MinElute gel extraction kit (Qiagen), the amplified PCR fragments were cloned into the pGEM-T easy vector (Promega, Madison, WI, USA), and recombinant plasmids were sequenced on both strands using an ABI3130xl Genetic Analyzer (Applied BioSystem). Genomic DNA sequences of representative alleles were deposited in GenBank (Acc no. MH444691-MH444693). Detection of genomic DNA polymorphisms and trait-genotype association analysis were performed as described previously [34]. Briefly, single nucleotide polymorphism (SNP) sites were determined using the program DNASP5.0 [35]. To exclude possible PCR errors, SNPs at a frequency below $5 \%$ were excluded for association analysis.

Genomic DNA samples were genotyped using 19 pairs of simple-sequence repeat (SSR) primers developed in eastern white pine [36]. A set of SSR polymorphic fragment was scored for the calculation of both $\mathrm{K}$ and $\mathrm{Q}$ matrixes as population structure. Significance of trait-genotype associations was computed using a mixed linear model $(M L M)(y=$ marker $+Q+K+e)$ using the software TASSEL [37].

\section{Protein over-expression in E. coli}

Because of its upregulation in $P$. monticola defense response and genetic association to QR to $C$. ribicola, PmPR10-3.1 was further selected for protein over-expression in E. coli. Based on its cDNA sequence (GenBank acc. AY596273), two PCR primers were designed and used to introduce the full-length coding sequence into the expression vector pET-3a (Novagen): forward primer (5'-CGT CGC CAT ATG GTG A GT GGG ACT GCA ACA AT-3') and reverse primer (5'-GCG GGA TCCTTA GCA GTA TAA GCT AAA GTT GGA GA-3'). The PCR fragment was first cloned into the pGEM plasmid (Promega). After sequencing verification, the gene was further inserted into PET-3a expression plasmid using the cloning site between the $\mathrm{Nde} \mathrm{I}$ and $\mathrm{BamH}$ I restriction sites.

The expression vector pET-3a-PmPR10-3.1 was introduced in E. coli cells, strain BL21 (DE3) pLysS. The transformed cells were grown at $37^{\circ} \mathrm{C}$ in LB culture supplemented with $100 \mu \mathrm{g} / \mathrm{ml}$ ampicillin and after they reached the logarithmic growth phase (OD600 1.0), protein expression was induced by $1.0 \mathrm{mM}$ IPTG. After 4 hours of growth at $37^{\circ} \mathrm{C}$, the cells were harvested by centrifugation, resuspended in lysis buffer, and sonicated. Cell debris was pelleted by centrifugation at $15,555 \mathrm{~g}$ and $4^{\circ} \mathrm{C}$ for 1 hour. Most of the PmPR10-3.1 protein was found in the insoluble fraction; therefore the precipitate was treated with 7.2 $\mathrm{M}$ urea. Renaturation of the protein was conducted by dialysis against $20 \mathrm{mM}$ Tris buffer, $\mathrm{pH} 8.0$ containing $5 \%$ glycerol and $5 \mathrm{mM} \beta$-mercaptoethanol. The dialysed fraction was clarified by 
centrifugation and applied to further purification on a HiPrep S300 (GE Healthcare) column. Two rounds of size exclusion chromatography were performed in $20 \mathrm{mM}$ Tris buffer, $\mathrm{pH} 8.0,5 \%$ glycerol, and $5 \mathrm{mM} \beta$ mercaptoethanol. To confirm whether PmPR10-3.1 recovered from inclusion bodies was proper folded, circular dichroism (CD) experiments were carried out in the far-UV region (205-265 nm). The CD spectra obtained were recorded with $100 \mathrm{~nm} / \mathrm{min}$ scan speed and 5 scans were averaged.

The protein was spun down in Millipore ultrafree-0.5 10K spin columns (Millipore Inc.) to remove any trace chemicals that might interfere with antifungal assays and also to concentrate the solution in the desalt buffer $(20 \mathrm{mmol} / \mathrm{L}$ Tris- $\mathrm{HCl}, \mathrm{pH} 7.0,0.15 \mathrm{~mol} / \mathrm{L} \mathrm{NaCl})$. Purified recombinant PmPR10-3.1 protein was applied to antifungal assays in concentrations varying from $10 \mu \mathrm{g} / \mathrm{mL}$ to $100 \mu \mathrm{g} / \mathrm{mL}$.

\section{Analysis of fungal spore germination rate}

The ascomycete Phoma exigua and P. argillacea were used to test PmPR10's effect on fungal spore germination. Fungal agar plugs were propagated on fresh potato dextrose agar (PDA; Difco) for at least 14 days, at $20^{\circ} \mathrm{C}$, with $50 \%$ humidity, under continuous light to stimulate sporulation. Mature conidiospores were harvested by flooding the culture plate with sterile distilled $\mathrm{H}_{2} \mathrm{O}$. The spore suspension was quantified using a haemocytometer and adjusted to approximately 1000 spores in $45 \mu \mathrm{L}$ volume of $0.1 \%$ water-agar.

To assess spore germination, the PmPR10-3.1 protein was applied directly to microcentrifuge tubes containing $45 \mu \mathrm{l}$ of each spore suspension in 0.1\% agar. The PmPR10-3.1 was added at final concentrations of $10 \mu \mathrm{g} / \mathrm{mL}$ and $42 \mu \mathrm{g} / \mathrm{mL}$, and water and desalt buffer were used as negative controls for each spore suspension. Tubes containing a mixture of spore suspension and each of the treatments were incubated at room temperature and spore germination rates were observed at the same time for both controls and protein treatment at 10,12, 14, 16, 18 and 20 hours post-incubation.

To quantify germination, at each time point, a small aliquot of the spore suspension was pipetted onto a glass slide and the number of germinating fungal spores per 100 count were determined using a Nikon, light microscope. The experiment was run on two different occasions in triplicate for each time point. An inhibition rate was calculated as $I=[(C-T) / C] * 100$, where $I=$ inhibition over control; $C=$ the highest count of germination (\%) in control; $\mathrm{T}$ = count of germination (\%) in samples with treatment. Student's t-test was used to assess the significance of the difference between control and treatment, and two-way ANOVAs were performed to determine the effect of different PmPR10-3.1 treatments on spore germination and hyphal growth across all tested fungal isolates.

\section{Assessing the effect of PR10 on hyphal tip growth and morphology}


Urediospores of Cronartium ribicola andconidia of $P$. exigua were used for the assessment of hyphal tip morphology and growth rate. Spore suspensions of each fungal species were diluted in $0.1 \%$ water-agar, and dispensed into $1.5 \mathrm{~mL}$ microcentrifuge tubes for each treatment. In separate tubes, the PmPR10-3.1 protein was applied to the $P$. exigua spore suspension at final concentrations of $10 \mu \mathrm{g} / \mathrm{mL}, 42 \mu \mathrm{g} / \mathrm{mL}, 75$ $\mu \mathrm{g} / \mathrm{mL}$, and $100 \mu \mathrm{g} / \mathrm{mL}$, and to $C$. ribicola spore suspension at $100 \mu \mathrm{g} / \mathrm{mL}$. Desalt buffer and double distilled $\mathrm{H}_{2} \mathrm{O}$ were used as negative controls. The spore suspensions were incubated for $18 \mathrm{hrs}$ and $24 \mathrm{hrs}$ for $P$. exigua and $C$. ribicola respectively. Following this incubation period, hyphal tip length was measured and morphology was observed for each spore suspensionusing a Zeiss Axio Imager A1 (Jena, Germany) with a Lumenera Infiniti 3 camera using software to capture images and measure fungal hyphal length.

\section{Results}

\section{Identification of PmPR10 genes expressed in western white pine}

A Blastx search revealed that western white pine primary needle and stem transcriptomes each contained 26 transcripts encoding proteins with significant sequence homology to typical PR10 proteins. After removal of repetitive and partial sequences, 10 unique PR10 proteins were identified with full-length amino acid sequence (Table S2). The putative PmPR10 proteins varied significantly throughout the total lengths, and the amino acid identities among PmPR10s ranged from $18.67 \%$ to $94.44 \%$ (Table S3). Only seven amino acid sites were identical across all sequences, including three glycine residues in a glycinerich P-loop motif (G-X-G-X-X-G) (Supplementary Fig. S1). Of the 10 unique PmPR10s, SN176002-c0-seq1, S172011-c0-seq1, and S170694-c1-seq1 encoded PmPR10-1.10, PmPR10-2.1, and PmPR10-3.1 proteins, respectively; which were reported previously (Liu and Ekramoddoullah 2004). The other seven novel members have been first identified in the complex PmPR10 class, including two typical PR10s encoded by N141673-c1-seq1 and S170013-c0-seq2 and five PR10-like proteins encoded by SN168113-c0-seq1, S162003-c0-seq2/seq3, and N143454-c0-seq1/seq2. According to usual nomenclature, the proteins encoded by N141673-c1-seq1 and S170013-c0-seq2 have been named as PmPR10-4.1 and PmPR10-4.2, respectively. PmPR10.4.1 and PmPR10-4.2 shared $82.17 \%$ amino acid identity. As compared to other known PmPR10s, they showed the highest amino acid identities of $67.95 \%$ and $66.46 \%$ to PmRP10-1.13 (GenBank Acc no AAL50006), respectively.

\section{Phylogenetic analysis of putative PR10 proteins in closely related five-needle pines}

To explore the evolutionary relationship of the PR10 families in five-needle pines, we conducted a search for PR10 sequences in other related five-needle pine species within the availabile genomic resources. PR10 members were found in the whitebark pine and limber pine transcriptomes and in the sugar pine 
genome by Blast analysis using PmPR10s as query. A total of 6, 6, and 45 unique PR10 homologs with approximate full-length sequences were unveiled in whitebark pine, limber pine, and sugar pine respectively. Phylogenetic analysis showed three clear clusters in the tree (Fig. 1); one grouped all genuine PR10 proteins while the other two clusters (PR10-like I and II) represented PR10-like sequences. Four subclusters (I to IV) were detected in the PR10 group. The first three subclusters were represented by PmPR10-1, PmPR10-2, and PmPR10-3. The forth subcluster contained two novel PR10s (PmPR10-4.1 and PmPR10-4.2 encoded by N141673-c1-seq1 and S170013-c0-seq2) and their orthologs and homologs from limber pine and sugar pine. Across four species of five-needle pines, PR10s contained a typical Ploop motif (G-D-G-G-V-G) while a much less conserved sequence (G-x-G-x-x-G) was revealed in the PR10like proteins. Remarkably, family members in the same clusters from different species had protein sequence identities much higher than those in different clusters from the same species, which implied a relatively high synteny between the same cluster/subcluster across different five-needle pine species.

\section{Transcript profiling of PmPR10 genes}

All full-length PmPR10s identified in the transcriptomes were included for a gene expression analysis. Based on available RNA-seq data from GenBank, expression profiles of the PmPR10 family were assessed in the tree tissues post $C$. ribicola infection (Fig. 2). Of all analyzed transcripts, three PmPR10 transcripts were significantly regulated with different patterns in the primary needles during early stages post rust infection. SN176002-c0-seq1 (PmPR10-1.10) was highly up-regulated at 4-dpi (days post infection) in both resistant (Cr2/-) and susceptible (cr2/cr2) seedlings; S170694-c1-seq1 (PmPR10-3.1) was up-regulated at 4-dpi only in susceptible seedlings; and SN168113-c0-seq1 (PR10-like II) was downregulated at 4-dpi only in resistant seedlings. When stem tissues at late rust infection stage were compared, N141673-c1-seq1 (PmPR10-4.1) and SN168113-c0-seq1 (PR10-like II) showed transcript levels significantly lower in cankered stems of susceptible seedlings than in canker-free stems of resistant seedlings. In contrast, the opposite pattern was observed for all four PmPR10-3.1-encoding transcripts (S170694-c1-seq1 to -seq4), which showed transcript levels significantly higher in cankered susceptible stems than in canker-free resistant stems, fold changes reaching 3.3 to 7.9. Taken together, these global gene expression profiles demonstrated that members of the PmPR10 class are differentially regulated upon infection by $C$. ribicola. Up-regulation of transcripts by rust infection in needle tissues suggests that PmPR10-3.1 may be an important component of tree defense response against biotic stressors.

\section{PmPR10-3.1 DNA variations are associated with western white pine partial resistance to WPBR}

Survival rates post rust infection varied greatly among seed families. Rust killed about $80 \%$ of total $C$. ribicola-infected seedlings in five years post inoculation, ranging from $11.8 \%$ up to $96.3 \%$ among different seed families. For all seedlings used in the association study, $15.4 \%, 20.5 \%, 38.5 \%$, and $25.6 \%$ were 
grouped into phenotypic categories: rust dead ( $Q R$ level at 0), normal canker (QR level at 1 4), bark reaction (QR level at 6 8), and stem symptom-free (QR level at 10), respectively (Supplementary Fig. S2).

PmPR10-3.1 genomic DNA fragments were sequenced in a breeding collection of 18 seed families. Sequence alignment analysis detected a total 21 SNP loci among the analyzed seedlings and they were further used in association analysis. In addition, 40 SSR polymorphic DNA fragments were detected and used to estimate population structure among seed families

The SNP loci within PmPR10-3 included four synonymous SNPs in the exons and intron and 17 nonsynonymous SPNs (ns-SNP) that cause amino acid changes in the putative proteins. MLM-based association analysis indicated that eight ns-SNPs were significantly associated $(p<0.05)$ with quantitative disease resistance against $C$. ribicola. The SNP-based coefficient of relationships explained proportions of phenotypic variation $\left(R^{2}\right)$ in a range from $4.04 \%$ to $8.71 \%$ (Supplementary Table S4).

The ns-SNP locus g178t showed trait-genotype association at the highest level with statistical significance $\left(R^{2}=8.71 \%, p=0.0013\right)$. The ns-SNP loci g178t and a180t caused amino acid changes at position $44\left(\mathrm{Val}_{44} / \mathrm{Leu}_{44} / \mathrm{Phe}_{44}\right)$, as counting from the start codon, located at the beginning of the conserved P-loop region. Tree genotypes for different protein isoforms, derived at the $\mathrm{Val}_{44} / \mathrm{Leu}_{44} / \mathrm{Phe}_{44}$ position, showed significant difference of quantitative resistance to $C$. ribicola (one way ANOVA test $p=$ 0.0021). The genotypes $\mathrm{Val}_{44} / \mathrm{Val}_{44}$ and $\mathrm{Phe}_{44} / \mathrm{Leu}_{44}$ showed resistance levels significantly higher than the genotypes $\mathrm{Phe}_{44} / \mathrm{Phe}_{44}$ and $\mathrm{Phe}_{44} / \mathrm{Val}_{44}$ (t-test $p$ values $0.00019-0.03613$ ). The genotype $\mathrm{Leu}_{44} / \mathrm{Leu}_{44}$ exhibited medium levels of quantitative resistance, with no significant difference from the other four genotypes (Fig. 3).

\section{Recombinant PmPR10-3.1 protein showed anti-fungal activity}

Recombinant PR10-3.1 protein was purified and used for an anti-fungal assay (Supplementary Fig. S3). Overall PmPR10-3.1 significantly inhibited spore germination of $P$. exigua and $P$. argillacea over a 20 hour (hr) time trial (Fig. 4). This was particularly evident at $10 \mathrm{hr}, 12 \mathrm{hr}$, and $14 \mathrm{hr}$ post-treatment where, regardless of the amount of protein used, the germination rates of treated spores were significantly lower than that of the control for both $P$. exigua and P. argillacea. The protein at concentrations of $10 \mu \mathrm{g} / \mathrm{mL}$ showed inhibitory effects up to 20 -hr post treatment in $P$. exigua (Fig. 4a). In $P$. argillacea, the inhibitory effect showed a dos-effect and lasted longer (from $14 \mathrm{hr}$ to $20 \mathrm{hr}$ ) when protein at higher concentration was used $(42 \mu \mathrm{g} / \mathrm{mL}$ vs. $10 \mu \mathrm{g} / \mathrm{mL})$. From the $16 \mathrm{hr}$ time point onwards, treatments of $P$. argillacea with $10 \mu \mathrm{g} / \mathrm{mL}$ PmPR10-3.1 protein did not significantly inhibitory effect compared to the controls (Fig. 4b).

The effect of PmPR10-3.1 on P. exigua and C. ribicola hyphal length was significant both in terms of morphological changes observed under the microscope as well as in absolute differences in hyphal length. As shown in Fig. 5, one way ANOVA on ranks revealed a significant difference in $P$. exigua hyphal 
length between treatments and controls $(\mathrm{p}<0.001)$. The hyphal growth further decreased significantly $(p$ $<0.0001$ ) when PmPR10-3.1 concentration increased from $42 \mu \mathrm{g} / \mathrm{mL}$ to $75 \mu \mathrm{g} / \mathrm{mL}$ (Fig. 5a). At the morphological level, germinating spores treated with PmPR10-3.1 showed much more hyphal tip abnormalities (Fig. 6a-f). In water and desalt buffer treatments the spores grew long hyphal strands which appeared normal (Fig. 6a-b). With the PmPR10-3.1 treatments (Fig. 6c-f) we observed swelling of the hyphal tips and branching of the very end of the hyphal tips. These abnormal growth patterns indicate a potential weakening of the cell wall due to exposure to the antifungal protein. Taken together, all of these results demonstrated that PmPR10-3.1 delayed fungal spore germination and hyphal tip growth, and caused morphological changes in hyphal tips.

Similar effects was observed for C. ribicola during urediospore germination (Fig. 5b, Fig. 6g-i). Following treatment of $100 \mu \mathrm{g} / \mathrm{mL}$ of PmPR10-3.1, C. ribicola hyphae growth decreased about three times with swelling of the hyphal tips compared to negative water control (t-test, $\mathrm{P}<0.001)$.

\section{Discussion}

This study characterized the PR10 class and revealed genetic and functional contributions of the gene members to tree QR against $C$. ribicola in western white pine. Pyramiding of QTLs or combining QR with MGR is becoming an important strategy for durable resistance to pathogens and pests in plant breeding [38]. Accordingly, the highest value of QR in breeding programs of five-needle pines is to protect MGR from $C$. ribicola virulent strains by combining QR and MGR mechanisms in elite seed orchards [39]. Given the importance of PR genes in the plant defense response, identification of novel family members and characterization of their genetic and functional contributions to QR is a key step towards practical utilization of this strategy in forest breeding programs for long-term management of WPBR. Causal genes underlying plant QR have been characterized with molecular roles in initial perception of pathogens (NBLRR and RLK), signal transduction, and downstream defense and host metabolism [38]. As one group of defense components, PR10s have been identified in a number of plant species from moss, gymnosperms, to higher angiosperm plants [16]. Differential expression of PR10 genes in responses to biotic and abiotic stressors implied their potential roles in plant immunity systems. To date, several studies were reported on the genomic organization, evolution, and functions of the PR10 family [40]), but such analyses for conifers are scarce [18].

In this study, we first performed a comprehensive search in available genomic resources for the expressed genes that belong to the PR10 family in western white pine and related five-needle pine species. In addition to those PmPR10 genes reported previously [27], we identified seven novel PR10 and PR10-like genes. It is worth noting that the PmPR10 family members may be more numerous because partial transcripts encoding incomplete ORFs were excluded for further analysis. Based on alignment analysis of the PR10 sequences retrieved for four species of five-needle pines, a phylogenetic analysis grouped these sequences into three clusters, one consisting of typical PR10s with four subclusters and two PR10-like groups (Fig. 1). Genetic distances were much longer among intraspecific paralogs than interspecific orthologous members in the subgenus Strobus, providing new insights into the evolutionary relationship 
among members of the PmPR10 family. This syntenic pattern detected between western white pine and closely related five-needle pines suggested that six common progenitors arose before the divergence of these species (Fig. 1).

The transcriptome-wide identification of PmPR10 genes allowed a further global gene expression analysis to profile expression patterns of the family members in response to WPBR infection using available RNA-seq data. Differential expression patterns suggested distinct biological roles in response to rust infection for different members of the PmPR10 family (Fig. 2). Host QR to C. ribicola usually displayed as a late defense response occurring in the stem tissues, showing different levels of canker damage and severity, ranging from normal canker, partial bark reaction with incomplete inhibition of fungal growth, complete bark reaction without fungal activity inside stem tissues, to symptom-free stems [41]. Consistent with that, PmPR10-3.1 orthologs were upregulated in whitebark pine upon treatment of methyl jasmonate, suggesting its role in conifer induced systematic resistance [42]. Contrary to PmPR103.1, PmPR10-4.2 (N141673-c1-seq1) and PmPR10-like II (SN168113-c0-seq1 exhibited constitutive expression at higher levels in the stems of resistant genotype, suggesting yet another role of PmPR10 proteins in the plant immune system. The present work provides new insight into the evolution and regulation of the PmPR10 class, as targets for inclusion in molecular breeding programs of five-needle pines for long-term management of WPBR.

We also performed an association study to test whether PmPR10s are among candidates for participating in the QR mechanism for rust resistance. Several previous studies investigated candidate genes for host QR to $C$. ribicola by SNP genotyping in populations of a few five-needle pines species, suggesting that variants of defense-related genes were main contributors of some resistance genotypes $[26,34,43]$. In the present study, based on the patterns of differential gene expression, PmPR10-3.1 was selected and scanned for its genomic variations. Mapping multiple SNP loci with small phenotypic effect suggests that PmPR10-3.1 may be one of the components in western white pine QR to C. ribicola. In particular, we were able to link the most significant ns-SNP locus to an amino acid change site close to the conserved P-loop motif. This potential functional change might present a causal variant as a beneficial allele to resistance, making PR10 a source of genes for selection of genotypes and enhancement of QR to decrease infection probability and WPBR severity in high biohazard regions.

Finally, genetic contribution of PmPR10-10-3.1 to western white pine QR to C. ribicola was verified by a functional analysis using in-vitro anti-fungal arrays. Several PR10 genes have been reported with in-vitro anti-microbial activities or enhanced resistance against pathogens by gene-over-expression studies $[2,3$, 14]. Our confirmation of delayed spore germination as well as reduced hyphal tip growth and morphological changes of $C$. ribicola and two ascomycete species indicated PmPR10-3.1 to be an antifungal component in host QR against a broad spectrum of pathogens. We observed that the in-vitro anti-fungal activity of the recombinant PR10 protein was reduced as time progressed, and became less effective without replenishment of the protein extract. Additionally fungal proteases may have been released to counteract the effect of the protein. 
As plant PR10 members are now well recognized as versatile binders of various small molecules, including phytohormones $[44,45]$ and other metabolites $[4,21,46]$, it might be argued that the anti-fungal activity of our PmPR10-3.1 preparations was connected with some unknown molecular cargo delivered in complex with the protein. This argument can be firmly dismissed because, serendipitously, the recombinant protein was purified from inclusion bodies using urea solubilization and refolding steps.

In previous studies, most QR causal genes showed partial phenotypic effects with molecular functions in the downstream defense mechanisms; the proteins encoded by these genes included PR proteins of various classes as well as enzymes from synthetic pathways of different secondary metabolites $[47,48]$. In addition to PmPR10-3.1, previous studies revealed anti-fungal activity of an anti-microbial peptide [49, 50], and association of a specific chitinase isoform with host QR in the WPBR pathosystem [34]. Although each gene of the polygenic QTL usually contributes a small phenotypic effect, the concerted action of several genes may explain the total resistance phenotypic traits against pathogen attacks [51]. Thus, PmPR10-3.1 might be working synergistically with other PR classes in enhancing QR to $C$. ribicola. Although QTLs and the regulatory networks that confer QR to $C$. ribicola await further molecular dissections in the subgenus Strobus, our results suggest that components of different PR families integrate together, conferring synergistic effect in the WPBR pathosystem. Both resistance mechanisms and the number of genes controlling the trait are critical factors affecting QR durability [52]. As advanced genomics approaches are used to dissect QTLs and QR mechanisms in non-model plants, more conifer genes will be identified for functional verification in the WP-BR interactions. A genomics-based platform derived from them would provide effective and efficient tools for screening of designed genotypes with expected resistance traits of adaptive significance.

\section{CONCLUSION}

In conclusion, expression of a complex PR10 family was investigated in the $P$. monticola transcriptomes. Due to its significant regulation during defense response, PmPR10-3.1 was selected for association study and in-vitro anti-fungal assays. Significant association of allelic variations with phenotypic traits related QR to WPBR and inhibitory effects of recombinant protein on $C$. ribicola and other fungal pathogens indicate that PmPR10-3.1 is one component in the P. monticola immune system with potential function in tree resistance. Because population size was limited and percentage of phenotypic variations explained by SNPs within PmPR10-3.1 were low in our association analysis, more research is required to confirm whether there truly is a genetic contribution of PR10 genes to $P$. monticola QR against WPBR. Allelic differential expression analysis would provide an efficient method for precise prediction of QR-causing genes. A further in-planta functional validation of PmPR10 will be performed using an experimental system of five-needle pines.

\section{Abbreviations}


MGR: major gene resistance; MLM: mixed linear model; PR: pathogenesis-related; QR: Quantitative resistance; QTL: quantitative trait loci; RPKM: reads per kilobase of transcript per million mapped reads; SNP: single nucleotide polymorphism; WPBR: white pine blister rust;

\section{Declarations}

Ethics approval and consent to participate: Not applicable.

Consent for publication: Not applicable.

Availability of data and material: All data generated or analyzed during this study are included in this article. DNA sequences were deposited in GenBank.

Competing interests: The authors declare that they have no competing interests.

Funding: This study was supported in part by the CFS-GRDI fund awarded to JJL.

Authors' contributions: Conceived and designed the experiments: JJL, HF, AZ, MS, MJ, RAS. Analyzed the data: JJL, AZ, HF, RAS. Contributed reagents/materials/analysis tools: JJL, MS, MJ, RAS. Wrote the paper: JJL, HF, AZ; and all authors read and approved the manuscript.

\section{Acknowledgements}

We thank G. Roke and G. Sumampong for providing fungal isolates; P. Rajkumar, G. Ross, K. Acharya, L. Baerg, G. Sumampong, M. Girard-Martel, and T. Holmes for their technical supports.

\section{References}

1. Van Loon LC, Rep M, Pieterse CMJ. Significance of inducible defense related proteins in infected plants. Annu Rev Phytopathol. 2006; 44:135-162.

2. Fernandes H, Michalska K, Sikorski M, Jaskolski M. Structural and functional aspects of PR-10 proteins. FEBS J. 2013; 280:1169-1199.

3. Agarwal P, Agarwal PK. Pathogenesis related-10 proteins are small, structurally similar but with diverse role in stress signaling. Mol Biol Rep. 2014; 41:599-611.

4. Mogensen JE, Wimmer R, Larsen JN, Spangfort MD, Otzen DE. The major birch allergen, Bet v 1 , shows affinity for a broad spectrum of physiological ligands. J Biol Chem. 2002; 277:23684-23692.

5. Zhou XJ, Lu S, Xu YH, Wang JW, Chen XY. A cotton cDNA: GaPR-10, encoding a pathogenesis-related 10 protein with in vitro ribonuclease activity. Plant Sci. 2002; 162:629-636. 
6. Wu F, Yan M, Li Y, Chang S, Song X, Zhou Z, Gong, W. cDNA cloning, expression, and mutagenesis of a PR-10 protein SPE-16 from the seeds of Pachyrrhizus erosus. Biochem Biophys Res Commun. 2003; 312:761-766.

7. Park CJ, Kim KJ, Shin R, Park JM, Shin YC, Paek KH. Pathogenesis-related protein 10 isolated from hot pepper functions as a ribonuclease in an antiviral pathway. Plant J. 2004; 37:186-198.

8. Chadha P, Das RH. A pathogenesis related protein, AhPR-10 from peanut: an insight of its mode of antifungal activity. Planta. 2006; 225:213-222.

9. Pungartnik C, da Silvan AC, de Melo SA, Gramacho KP, de Mattos Cascardo JC, Brendel M, Micheli F, da Silva Gesteira A. High-affinity copper transport and Snq2 export permease of Saccharomyces cerevisiae modulate cytotoxicity of PR-10 from Theobroma cacao. Mol Plant Microbe Interact. 2009; 22:39-51.

10. Xie YR, Chen ZY, Brown RL, Bhatnagar D. Expression and functional characterization of two pathogenesis-related protein 10 genes from Zea mays. J Plant Physiol. 2010; 167:121-130.

11. Gómez-Gómez L, Rubio-Moraga A, Ahrazem O. Molecular cloning and characterisation of a pathogenesis-related protein CsPR10 from Crocus sativus. Plant Biol (Stuttg) 2011; 13:297-303.

12. Agarwal P, Bhatt V, Singh R, Das M, Sopory SK, and Chikara J. Pathogenesis-related gene, JcPR-10a from Jatropha curcas exhibit RNase and antifungal activity. Mol Biotechnol. 2013; 54:412-425.

13. Fan S, Jiang L, Wu J, Dong L, Cheng Q, Xu P, Zhang S. A Novel pathogenesis-related class 10 protein Gly $\mathrm{m} 4 \mathrm{l}$, increases resistance upon Phytophthora sojae Infection in soybean (Glycine max [L.] Merr.). PLoS ONE. 2015; 10:e0140364.

14. Jain $S$, Kumar A. The Pathogenesis related class 10 proteins in plant defense against biotic and abiotic stresses. Adv Plants Agric Res. 2015; 2:00077.

15. Agarwal P, Dabi M, More P, Patel K, Jana K, Agarwal PK. Improved shoot regeneration, salinity tolerance and reduced fungal susceptibility in transgenic tobacco constitutively expressing PR-10a gene. Front Plant Sci. 2016; 7:217.

16. Castro A, Vidal S, de León IP. Moss pathogenesis-related-10 protein enhances resistance to Pythium irregulare in Physcomitrella patens and Arabidopsis thaliana. Front Plant Sci. 2016; 7:580.

17. Han X, He X, Qiu W, Lu Z, Zhang Y, Chen S, Liu M, Qiao G, Zhuo R. Pathogenesis-related protein PR10 from Salix matsudana Koidz exhibits resistance to salt stress in transgenic Arabidopsis thaliana. Environmental and Experimental Botany. 2017; 141:74-82.

18. Liu J-J, Ekramoddoullah AK. The family 10 of plant pathogenesis-related proteins: their structure, regulation, and function in response to biotic and abiotic stresses. Physiol Mol Plant Pathol. 2006; 68:313. 
19. Biesiadka J, Bujacz G, Siorski MM, Jaskolski M. Crystal structure of two homologous pathogenesisrelated proteins from Yellow Lupine. J Mol Biol. 2002; 319:1223-1234.

20. Sliwiak J, Dauter Z, Jaskolski M. Crystal structure of Hyp-1, a Hypericum perforatum PR-10 protein, in complex with melatonin. Front Plant Sci. 2016; 7:1-10.

21. Sliwiak J, Sikorski M, Jaskolski M. PR-10 proteins as potential mediators of melatonin-cytokinin cross-talk in plants: crystallographic studies of LIPR-10.2B isoform from yellow lupine. FEBS J. 2018; 285:1907-1922.

22. Sniezko RA, Smith J, Liu J-J, Hamelin RC. Genetic resistance to fusiform rust in southern pines and white pine blister rust in white pines-A Contrasting tale of two rust pathosystems-Current status and future prospects. Forests. 2014; 5:2050-2083.

23. Kinloch BJr, Sniezko R, Dupper G. Virulence gene distribution and dynamics of the white pine blister rust pathogen in western North America. Phytopathol. 2004; 94:751-758.

24. Parlevliet JE. Durability of resistance against fungal, bacterial and viral pathogens; present situation. Euphytica. 2002; 124:147-156.

25. Liu J-J, Sniezko R, Murray M, Wang N, Chen H, Zamany A, Sturrock R, Savin D, Kegley A. Genetic diversity and population structure of whitebark pine (Pinus albicaulis Engelm.) in western North America. PLoS ONE. 2016a; 11:e0167986.

26. Vázquez-Lobo A, De La Torre AR, Martínez-García PJ, Vangestel C, Wegzryn JL, Ćalić I, Burton D, Davis D, Kinloch B, Vogler D, Neale DB. Finding loci associated to partial resistance to white pine blister rust in sugar pine (Pinus lambertiana Dougl.). Tree Genet Genom. 2017; 13:108.

27. Liu J-J, Ekramoddoullah AK. Characterization, expression and evolution of two novel subfamilies of Pinus monticola cDNAs encoding pathogenesis-related (PR) -10 proteins. Tree Physiol. 2004; 24:13771385.

28. Liu J-J, Sturrock RN, Benton R. Transcriptome analysis of Pinus monticola primary needles by RNAseq provides novel insight into host resistance to Cronartium ribicola. BMC Genomics. 2013; 14:884.

29. Liu J-J, Sniezko RA, Sturrock RN, Chen H. Western white pine SNP discovery and high-throughput genotyping for breeding and conservation applications. BMC Plant Biology. 2014; 14:380.

30. Stevens KA, Wegrzyn JL, Zimin A, Puiu D, Crepeau M, Cardeno C, Paul R, Gonzalez-lbeas D, Koriabine M, Holtz-Morris AE, Martínez-García PJ, Sezen UU, Marçais G, Jermstad K, McGuire PE, Loopstra CA, Davis JM, Eckert A, de Jong P, Yorke JA, Salzberg SL, Neale DB, Langley CH. Sequence of the sugar pine megagenome. Genetics. 2016; 204:1613-1626. 
31. Liu J-J, Schoettle AW, Sniezko RA, Sturrock RN, Zamany A, Williams H, Ha A, Chan D, Danchok D, Savin DP, Kegley A. Genetic mapping of Pinus flexilis major gene (Cr4) for resistance to white pine blister rust using transcriptome-based SNP genotyping. BMC Genomics. 2016; 17:753.

32. Tamura K, Peterson D, Peterson N, Stecher G, Nei M, Kumar S. MEGA5: Molecular evolutionary genetics analysis using maximum likelihood, evolutionary distance, and maximum parsimony methods. Mol Biol Evol. 2011; 28:2731-2739.

33. Radauer $\mathrm{C}$, Lackner $\mathrm{P}$, Breiteneder $\mathrm{H}$. The Bet $\mathrm{v} 1$ fold: an ancient, versatile scaffold for binding of large, hydrophobic ligands. BMC Evolutionary Biology. 2008; 8:286

34. Liu J-J, Sniezko RA, Ekramoddoullah AK. Association of a novel Pinus monticola chitinase gene (PmCh4B) with quantitative resistance to Cronartium ribicola. Phytopathol. 2011; 101: 904-911.

35. Librado P, Rozas J. DnaSP v5: A software for comprehensive analysis of DNA polymorphism data. Bioinformatics. 2009; doi: 10.1093/ bioinformatics/btp187.

36. Echt CS, May-Marquardt P, Hseih M, Zahorchak R. Characterization of microsatellite markers in eastern white pine. Genome. 1996; 39:1102-1108.

37. Bradbury PJ, Zhang Z, Kroon DE, Casstevens TM, Ramdoss Y, Buckler ES. TASSEL: Software for association mapping of complex traits in diverse samples. Bioinformatics. 2007; 23:2633-2635.

38. Pilet-Nayel M-L, Moury B, Caffier V, Montarry J, Kerlan M-C, Fournet S, Durel CE, Delourme R. Quantitative resistance to plant pathogens in pyramiding strategies for durable crop protection. Front in Plant Sci. 2017; 8:1838.

39. Kinloch BJr, Burton D, Davis DA, Westfall R, Dunlap J, Vogler DR, Sniezko RA, Yanchuk AD, Kliejunas JT, Palmieri KM, Alexander JM, Frankel SJ. Strong partial resistance to white pine blister rust in sugar pine, Proceedings of the fourth international workshop on the genetics of host-parasite interactions in forestry: Disease and insect resistance in forest trees, 2012 (tech. coords.) Gen Tech Rep. PSW-GTR-240. US Department of Agriculture, Forest Service, Pacific Southwest Research Station, Albany, CA, pp. 80-91.

40. Kosuth J, Hrehorova D, Jaskolski M, Cellarova E. Stress-induced expression and structure of the putative gene hyp-1 for hypericin biosynthesis. Plant Cell Tiss Organ Cult. 2013; 114:2007-2016.

41. Sniezko RA, Kegley AJ, Danchok R. White pine blister rust resistance in North America, Asian and European species-results from artificial inoculation trials in Oregon. Ann For Res. 2008; 51:53-66.

42. Liu J-J, Williams H, Li XR, Schoettle AW, Sniezko RA, Murray M, Zamany A, Roke G, Chen H. Profiling methyl jasmonate-responsive transcriptome for understanding induced systemic resistance in whitebark pine (Pinus albicaulis). Plant Mol Biol. 2017; 95:359-374. 
43. Liu J-J, Hammet C, Sniezko RA. Pinus monticola pathogenesis-related gene PmPR10-2 alleles as defense candidates for stem quantitative disease resistance against white pine blister rust (Cronartium ribicola). Tree Genet Genom. 2013; 9:397-408.

44. Pasternak O, Bujacz GD, Fujimoto Y, Hashimoto Y, Jelen F, Otlewski J, Sikorski MM, Jaskolski M. Crystal structure of Vigna radiata cytokinin-specific binding protein in complex with zeatin. Plant Cell 2006; 18:2622-2634.

45. Ruszkowski M, Sliwiak J, Ciesielska A, Barciszewski J, Sikorski M, Jaskolski M. Specific binding of gibberellic acid by cytokinin-specific binding proteins: a new aspect of plant hormone-binding proteins with PR-10 fold. Acta Cryst. 2014; D70:2032-2041.

46. Kofler S, Asam C, Eckhard U, Wallner M, Ferreira F, Brandstetter H. Crystallographically mapped ligand binding differs in high and low IgE binding isoforms of birch pollen allergen bet v 1. J Mol Biol. 2012; 422:109-123.

47. Kump KL, Bradbury PJ, Wisser RJ, Buckler ES, Belcher AR, Oropeza-Rosas MA, Zwonitzer JC, Kresovich S, McMullen MD, Ware D, Balint-Kurti PJ, Holland JB. Genome-wide association study of quantitative resistance to southern leaf blight in the maize nested association mapping population. Nat Genet. 2011; 43:63-168.

48. Belcher AR, Zwonitzer JC, Cruz JS, Krakowsky MD, Chung CL, Nelson R, Arellano C, Balint-Kurti PJ. Analysis of quantitative disease resistance to southern leaf blight and of multiple disease resistance in maize, using near-isogenic lines. Theor Appl Genet. 2012; 124:433-445.

49. Zamany A, Liu J-J, Ekramoddoullah AK, Sniezko R. Antifungal activity of a Pinus monticola antimicrobial peptide 1 (Pm-AMP1) and its accumulation in Cronartium ribicola-infected western white pine. Can J Microbiol. 2011; 57:667-679.

50. Verma SS, Yajima W, Rahman MH, Shah S, Liu J-J, Ekramoddoullah A K, Kav NNV. A cysteine-rich antimicrobial peptide from Pinus monticola (PmAMP1) confers multiple disease resistance in canola (Brassica napus). Plant Mol Biol. 2012; 79:61-74.

51. Roux F, Voisin D, Badet T, Balagué C, Barlet X, Huard-Chauveau C, Roby D, Raffaele S. Resistance to phytopathogens e tutti quanti: placing plant quantitative disease resistance on the map. Mol Plant Pathol. 2014; 15:427-432.

52. Mundt CC. Durable resistance: A key to sustainable management of pathogens and pests. Infect Genet Evol. 2014; 27:446-455.

\section{Supplementary Materials Legend}

\section{Electronic supplementary material:}


Table S1: Geographical locations of seed families used in the association study.

Table S2: Putative PR10 and PR10-like proteins in four species of five-needle pines (western white pine, sugar pine, limber pine, and whitebark pine).

Table S3: Amino acid sequence identities among members of the PmPR10 family.

Table S4: Association test of PmPR10-3.1 SNPs with mean levels of western white pine quantitative resistance to Cronartium ribicola.

Figure S1: Comparison of the full-length amino acid sequences deduced from PmPR10 genes expressed in the western white pine transcriptomes during defense in response to infection by Cronartium ribicola. Alignment analysis was performed using Clustal Omega. Seven residues identical in all proteins are highlighted with asterisks $\left({ }^{*}\right)$. The conserved substitutions with similar characteristics and semiconserved substitutions are labelled with (:) and (.), respectively. The P-loop motif (Gly47-Thr53) as positioned in PmPR10s is underlined. The polymorphic site (Phe44) of PmPR10-3.1 encoded by S170694_c1_seq1 is presented in bold letter.

Figure S2: Assessment of quantitative resistance (QR) levels among Pinus monticola seed families. (a) Percentage of rust-killed seedlings among different open-pollinated seed families. (b) Grouping of seedlings used in association study under different categories based on assessment of QR-related traits post rust infection. RD: rust-caused dead. NC: normal canker development. BR: bark reaction. SS-free: stem symptom-free.

Fig S3: Purification of recombinant PmPR10-3.1 protein using size exclusion chromatography on HiPrep S300 (GE Healthcare) column. The fractions of the protein peaks were analysed by $15 \%$ SDS-PAGE. The gel lanes were labeled for markers of standard proteins (M), control after dialysis and clarification (Cd), control after filtering and concentration (Cf), and fractions of the protein peaks collected from chromatography (numbed from 24 to 35 ).

\section{Figures}



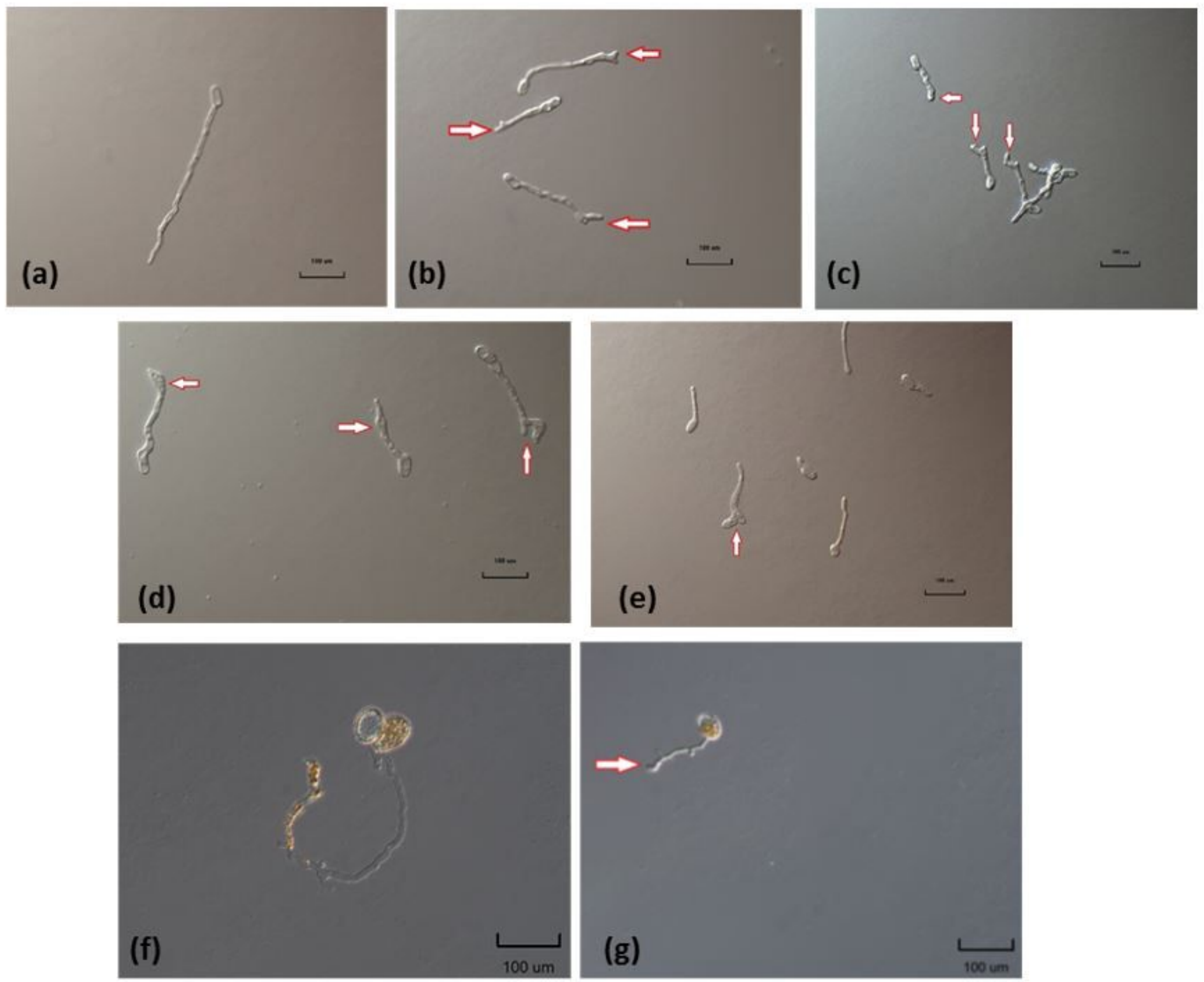

\section{Figure 1}

Microscopic photographs showing the effects of PmPR10 on spore germination of fungal pathogens. Conidiospores of Phoma exigua (isolate PFC 2705) were treated by pure PmPR10-3.1 protein for 18 hours and photographs were taken at 63X magnification DIC. (a) Desalt buffer control; (b) $10 \mu \mathrm{g} / \mathrm{mL}$ PR10; (c) $42 \mu \mathrm{g} / \mathrm{mL}$ PR10; (d) $75 \mu \mathrm{g} / \mathrm{mL}$ PR10; (e) $100 \mu \mathrm{g} / \mathrm{mL}$ PR10. Urediospores of Cronartium ibicola were treated with pure PmPR10-3.1 protein for 24 hours and photographs were taken at 200X using Nimarsky filter: (f) desalt buffer control; (g) $100 \mu \mathrm{g} / \mathrm{mL}$ PR10. Bars in insets represent $100 \mu \mathrm{m}$. Arrows indicated reduced hyphal growth and swelling at hyphal tips due to PmPR10-3.1 
(a)

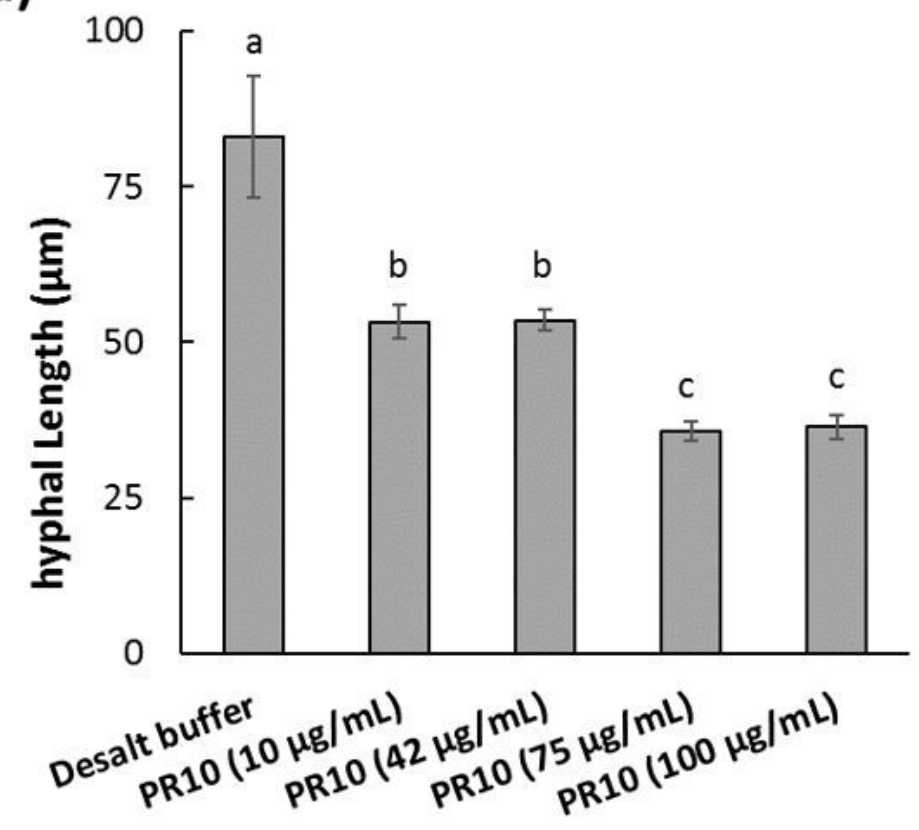

Treatment by PR10-3.1 protein (b)

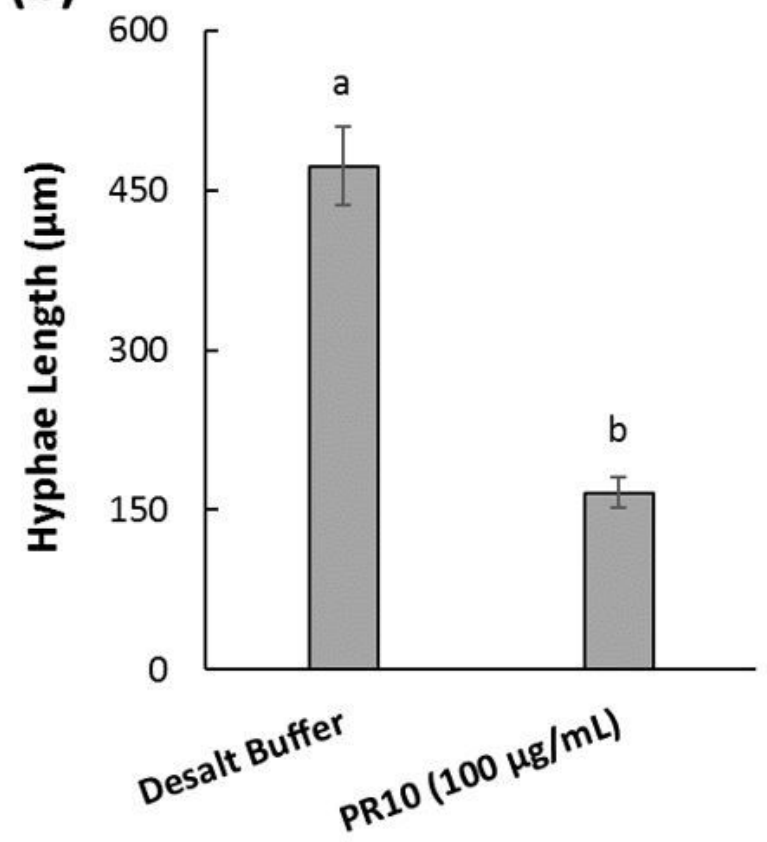

Treatment by PR10-3.1 protein

Figure 2

Effect of PmPR10 on hyphal growth of fungal pathogens. (a) Phoma exigua hyphal length $(\mu \mathrm{m})$ was measured at early spore germination stage (18 Hrs) with PmPR10-3.1 treatment at four different concentration. (b) Cronartium ribicola hyphal length $(\mu \mathrm{m})$ was measured at early spore germination stage (24 Hrs) with PmPR10-3.1 treatment at $100 \mu \mathrm{g} / \mathrm{mL}$. Bars represent means and standard error of the mean (SEM) of $20 \mathrm{C}$. ribicola or $30 \mathrm{P}$. exigua samples for each treatments. The hyphal strands of germinating spores were measured under the microscope. Different bar labels indicate significant differences among treatments $(p<0.001)$ using one way ANOVA or t-test.

(a)

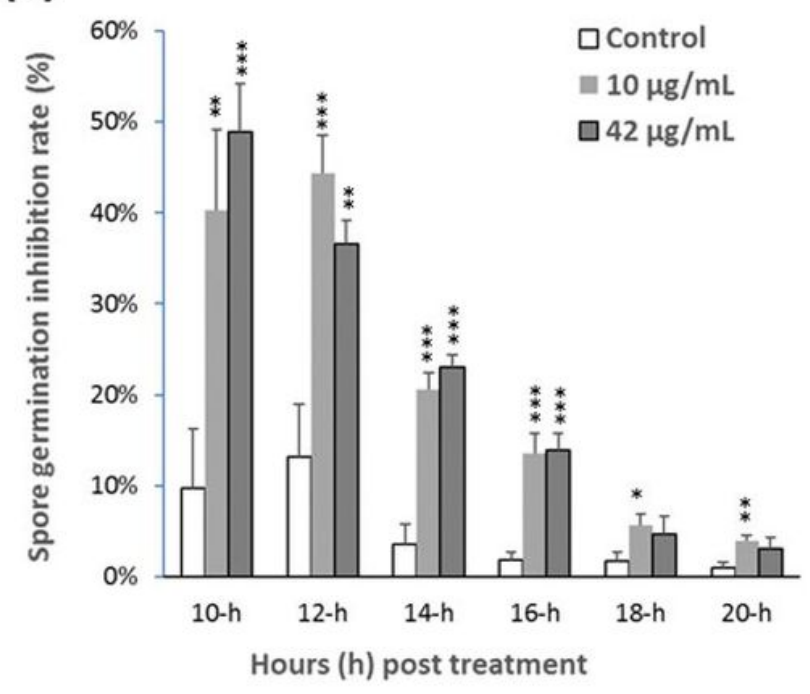

(b)

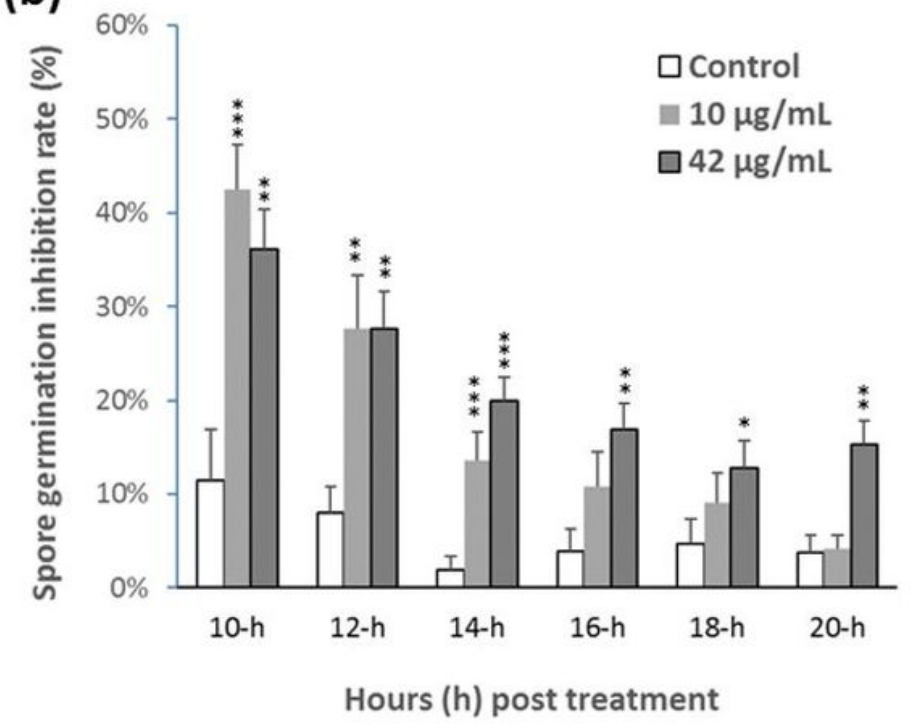


Figure 3

Inhibitory effect of PmPR10-3.1 on spore germination of fungal pathogens. (a) Phoma exigua; (b) P. argillacea. Control samples contained spore suspension with desalt buffer. Bars represent means and standard error of the mean (SEM) of two time trials, each with three repeats. Student's t-Test * $p<0.05$, ** $p<0.01, * \star * p<0.001$.

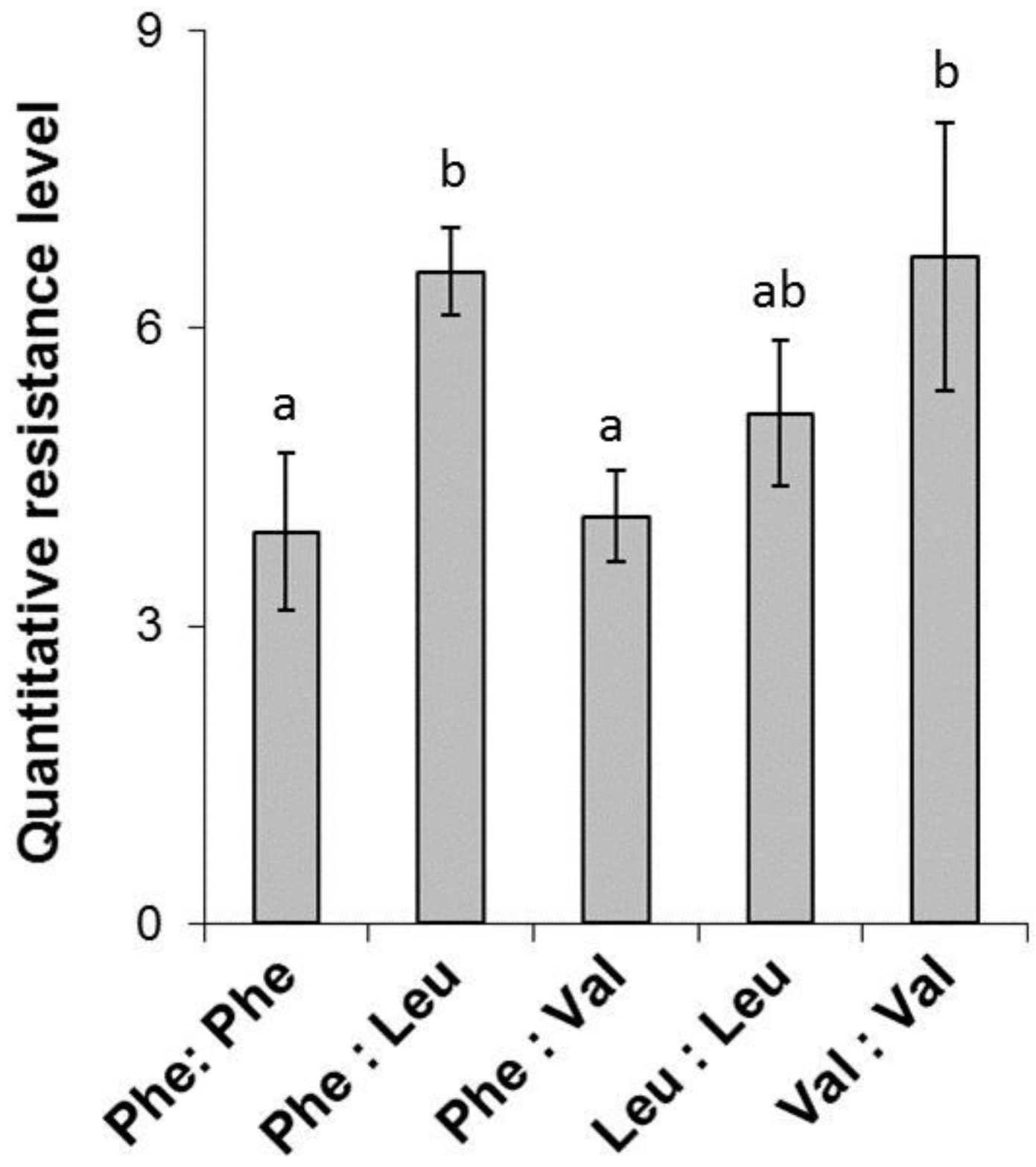

PmPR10-3.1 isoforms

Figure 4 
Association of genotypes of PmPR10-3.1 isoforms with quantitative resistance levels. Mean level of quantitative resistance was shown for five main genotypes. The genotype (Leu44/Val44) was excluded because it was detected in only one tree. Error bars showed standard error of the mean (SEM) based on the entire population of each genotype. Significant statistical differences (Student's t-test, $p<0.05$ ) between genotypes are labeled with different letters.

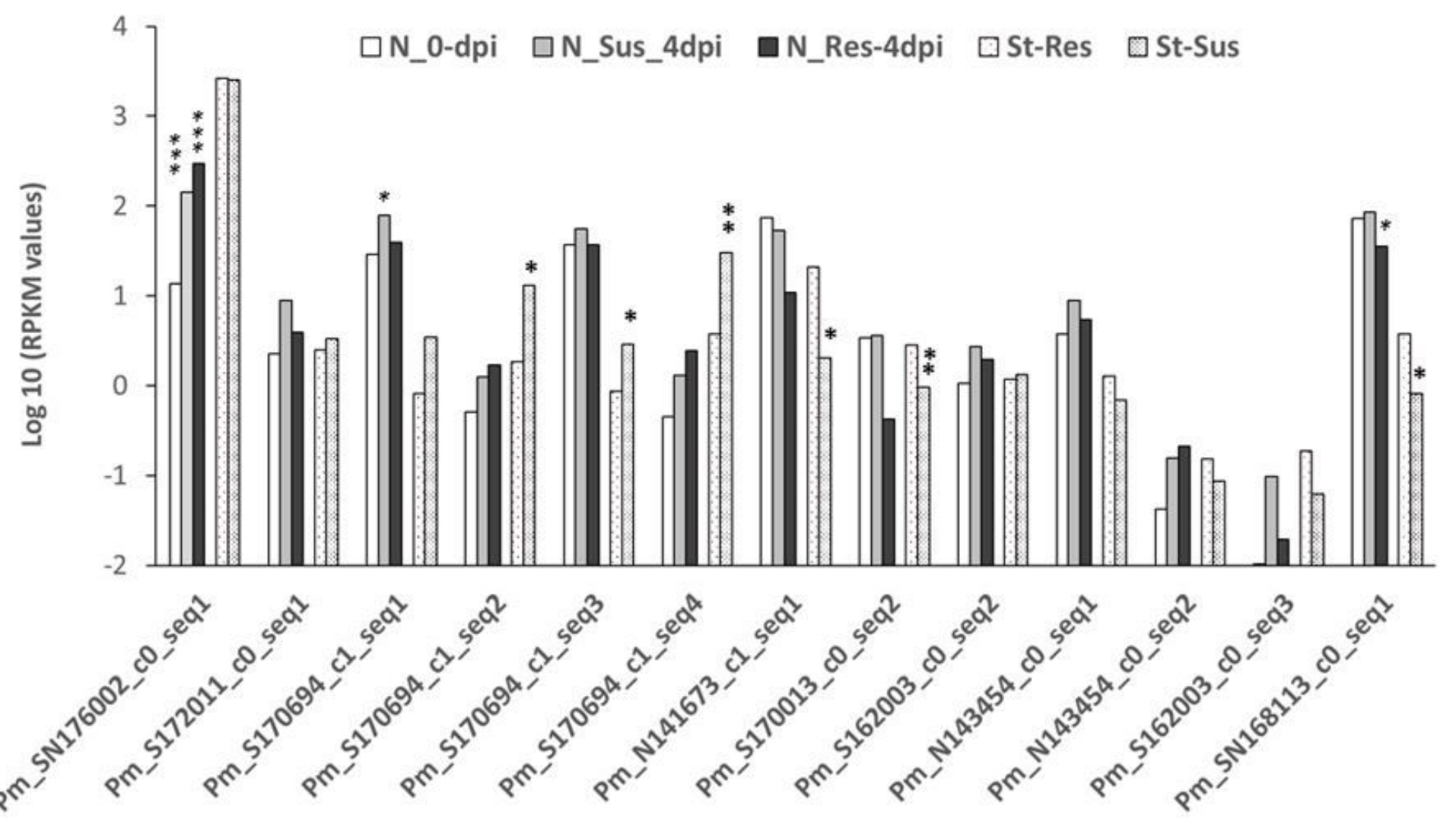

Figure 5

Transcript expression profiles of the Pinus monticola PR10 family in response to infection by Cronartium ribicola by RNA-seq analysis. Gene expression levels were evaluated by RPKM using the CLC program. N 0_DPI: needles of both resistant ( $\mathrm{Cr} 2 /-)$ and susceptible ( $\mathrm{cr} 2 / \mathrm{cr} 2)$ seedlings were sampled and mixed at 0 day with no infection (0_dpi); N-Res 4_DPI: needles of resistant seedlings were sampled at four days post infection; N-Sus 4_DPI: needles of susceptible seedlings were sampled at four days post infection. St-Res: healthy stem tissues were sampled from resistant seedlings (cankered-free); and St-Sus: cankered stems of susceptible seedlings were samples at 13 months post inoculation. Needle samples were analyzed by Kal's test with $p$ values corrected for false discovery rate-FDR and stem samples were analyzed by Student's t-test. $* p<0.05, * * p<0.01, * \star * p<0.001$. 


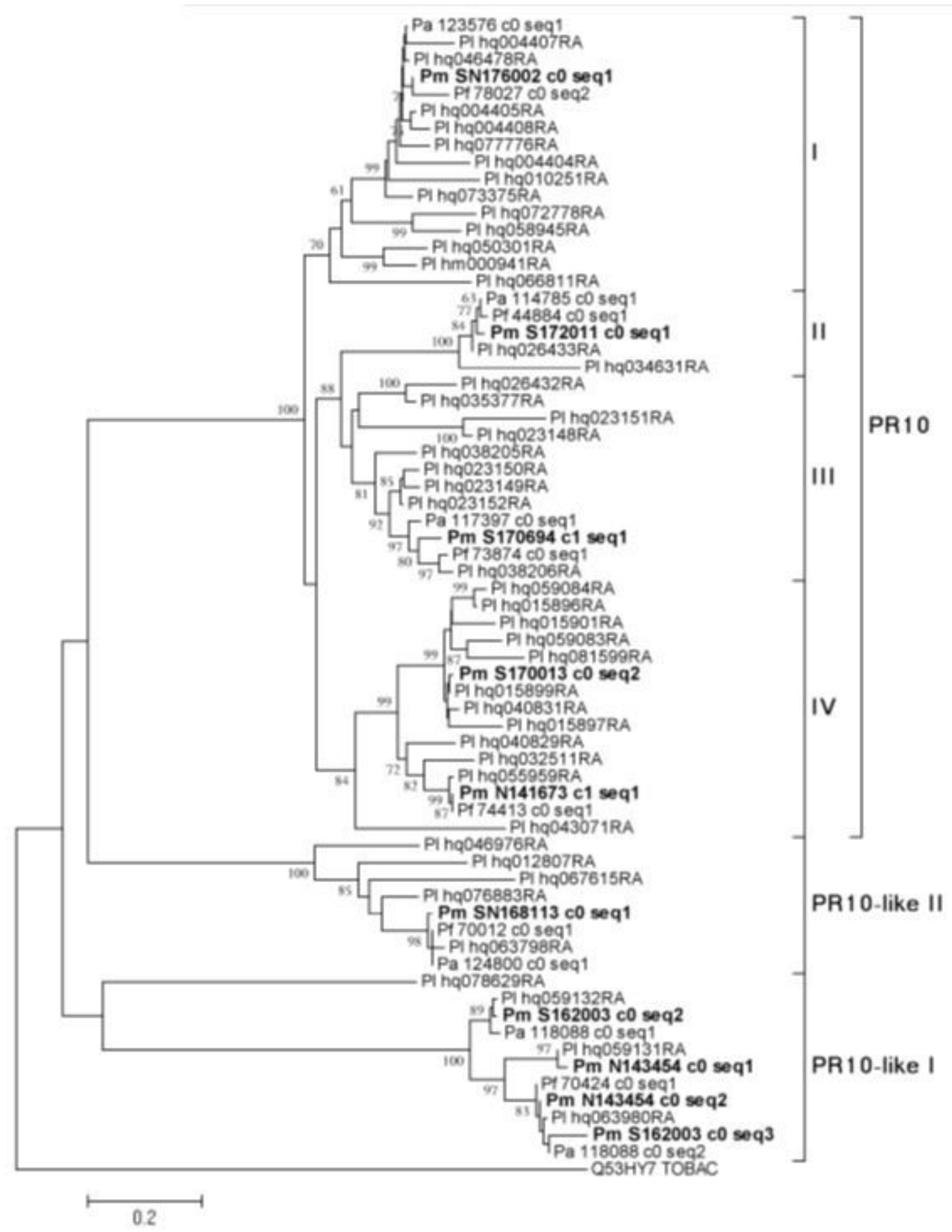

Figure 6

Phylogenetic analysis of putative PR10 and PR10-like proteins from four five-needle pines. Phylogenetic analysis was performed using program MEGA $v 5$. The graphic representation shows the results by the minimum evolution method. The scale indicates genetic distance proportional to the substitutions per site. In total, 6, 6, 10, and 45 putative proteins sequences were included for Pinus albicaulis (Pa), P. flexilis (Pf), P. monticola (Pm), and P. lambertiana (PI), respectively. Nicotiana tabacum polyketide cyclase (Q53HY7_TOBAC) was shown as an outgroup. 


\section{Supplementary Files}

This is a list of supplementary files associated with this preprint. Click to download.

- Fig.S3protein.pptx

- Fig.S2ResTrait.pptx

- TabS1S4.xlsx

- Fig.S1WWPaa10align.docx 